\title{
EL MODERNISMO EN EL URUGUAY
}

\author{
Ildefonso Pereda Valdés \\ Faculdade Catarinense de Filosofia
}

El modernismo fue uno de los movimientos de la literatura hispanoamericana que tuvo mayor repercusión en América y aún em España. Por primera vez la literatura de las antiguas colonias repercute en la Madre Patria y con un grito de emancipación colonialista, que se había iniciađo con el romanticismo, se termina con un tutelaje secular.

Para explicar tal fenómeno trazaremos un brevísimo panorama de la literatura hispanoamericana a fines del siglo XIX. Como lo dijera Rubén Darío - el piloto del navio modernista, se escribian en las Américas serviles imitaciones de la "Silva a la Agricultura de la Zona Tórrida" de Andrés Bello y del "Canto a Junin de Olmedo, predominando los temas didácticos $o$ heroicos con evidente tendencia neoclásica. E1 romanticismo, particularmente en España con Campoamor y Bartrina, había caido en un prosaismo seudo filosófico, sin emular ni superar el fino lirismo de Bécquer. La forma era despreciada cuando no abandonaåa. Nada podían encontrar en España o en América para superarse los nuevos cultores de una poesía que comenzaba a catalogarse en la estética del arte por el arte, de la forma pura y desinteresada, como lo son el arte de Rodó o Rubén Dario. No nos extrañemos si entonces los poetas, no siempre capaces de extraer de América el jugo de sus esencias infinitas, miraran hacia Francia. Ya lo habian hecho los románticos, siguiendo las huellas de Chateaubriand, Hugo o Lamartine.

Críticos del modernismo establecen la fecha de 1888, o sea la publicación de "Azul" como punto de partida del movimiento modernista: Rubén Dario fue su gestor y no tiene 
precursores o antecedentes importantes que le quiten la primacía. Otro criterio, hoy bastante extendido, es el que niega a Rubén Darío la absorbente personalidad que se le atribuyó en la escuela que fundara. Hay quienes ven en el nicaraguense genial un hábil arreglador de recursos y técnicas tomadas aquí y allá, artificiosamente urdidas y tejidas en una trama inconsútil. Rubén Darío no solo imitó a Verlaine, Banville, Poe, Lecomte de Lisle, sino que imitó el versolibrismo de Silva, la policromía de la prosa de Martí, la delicuescencia morbosa baudeleriana y nietzschiana de Julián d’el Casal, el parisinismo elegante de Gutierrez Nájera. Con todos estos elementos, y las recetas del simbolismo Rubén Darío habría elaborado sus sinfonías poéticas. Aceptar este tesis premodernista desconociendo el valor gestador de Rubén Darío significa negar su espíritu creador, su genial poder de sintesis, la variedad y riqueza de su estilo, y lo que parecería más extraño, su originalidad. Don Juan Valera con la sagacidad no siempre acertada de su ingenio, definió muy bien el aspecto combinatorio y selectivo de la obra de Rubén Darío, al decirle en la carta que le enviara desde España, publicada más tarde como prólogo a la segunda edición de "Azul"... "lo primero que se nota es que está usted saturado de todo lo más flamante de la literatura francesa: Hugo, Lamartine, Musset, Baudelaire, Lecomte de Lisle, Gautier, Bourget, Sully Prudhome, Daudet, Zola, Barbey D'Aurevilly, Catule Mendès, Rollinat, Goncourt, Flaubert y todos los demás poetas $\mathrm{y}$ novelistas han sido por usted bien estudiados y mejor comprendidos. $Y$ ud. no imita a ninguno: no es usted romántico, ni naturalista, ni neurótico, ni decadente, ni simbólico, ni parnasiano. Ud. lo ha revuelto todo: ha puesto a cocer en el alambique de su cerebro y ha sacado de ella una rica quinta esencia". No se puede negar que el modernismo alcanzó en sus estapas posteriores, con Julio Herrera y Reissig, Leopoldo Lugones, Horacio Quiroga, Chocano y Nervo, elaboraciones más trascendentes y un nuevo conteniơo que Rubén Darío solo pudo intuir en "Cantos de Vida y Esperanza"; pero el Modernismo sin Rubén Darío no hubiera triunfado en España $\mathrm{y}$. en toda América: 
se hubiera dispersado en focos locales, incapaces de alcanzar la proyección universal que le dió Rubén Darío. Las revistas del modernismo, La Revista Azul y la Revista de América difundieron las nuevas teorías estéticas; pero fueron Rubén Darío, Amado Nervo, Rufino Blanco Fombona, Gómez Carrillo y Díaz Rodriguez, quienes publicando sus libros en Paris o en Madrid, y en los últimos tiempos a través de la Revista "Mundial", quienes extendieron el campo de acción de la nueva escuela; más tarde, Rodó, Lugones, Herrera y Reissig, Quiroga, Jaimes Freyre, Guillermo Valencia, con un sentido más restrictivo en cuanto a publicidad, pues sus libros se eơitaron en Argentina, Uruguay, o Colombia, le dieron al modernismo un sentido más quintaseenciado a través de la prosa de Rodó diáfana y elegante, o del estilo barroco ảel lirismo de Herrera y Reissig. Coincide el modernismo con la decadencia de España y la pérdida de las últimas colonias: Cuba y Filipinas y con el despertar de la conciencia nacional que inicia la llamada generación del 98, con la que tiene afinidacies estéticas y políticas, porque el modernismo en América, tuvo sus proyecciones políticas antiimperialistas, y estéticamente, tanto el modernismo como la generación del 98, tienen el mismo fin de superación artística. Juan Ramón Jiménez y Rubén Darío, coinciden en ơistintos meridianos en las mismas inquietudes estéticas. En un reciente trabajo publicado en la Revista Nacional de Cultura, de Caracas, el escritor venezolano, Orlando Araujo, al hablar del modernismo y muy especialmente de la obra en prosa de Manuel Díaz Roöriguez, resume los principales caracteres del modernismo: anhelo de perfección formal que comprende tres aspectos: Esteticismo, innovaciones formales y culto de las sensaciones; el refinamiento de la imaginación, exotismo, con sus variantes geográficas: helenismo, orientalismo, siglo XVIII y literarias: parnasianismo y simbolismo francés; la exaltación de la fantasia: mitología clásica, nórdica, indigena pre colombina; cuentos fantásticos y la exaltación cie la vida espiritual con sus aspectos de desazón o conflicto espiritual o individualismo artístico. Creo que siendo muy completo este cuadro cabe agregar otros aspectos del modernismo: el 
mundonovismo, que tuvo su iniciación en "Cantos de Vida y Esperanza" de Rubén Darío, y se continúa con "Alma América" de Chocano, además de la influencia de Poe, de Whitman, de Ibsen, de Eugenio de Castro, Tolstoy y D'Annunzio.

En el Uruguay, el modernismo fue un movimiento de aclimatación momentánea, sin raíces profundas, pero con consecuencias benéficas para la literatura nacional. En el Brasil la palabra mođernismo se emplea con un significado diferente. Se llama "modernismo" al movimiento que se inicia en San Pablo en 1920 por un grupo de escritores de inicial tendencia futurista, que apoyó la obra de la pintora Anita Malfati y del escultor Brecheret, en la "Semana de Arte Moderna", movimiento de renovación que pilotearon los dos Anơrades, Paulo Prado, Guilherme de Almeida y $\mathrm{Me}^{-}$ notti del Pichia, con la complicidad en Río de Janeiro, del pintor Di Cavalcanti, y los poetas Ronald de Carvalho, Manuel Bandeira, Renato Almeida y Ribeiro Couto, que recibió gran impulso con el apoyo de Graça Aranha, que renunció al acaờmismo para defender aquel arte que Monteiro Lobato había llamado de "mistificación o paranoia". Yo tam" bién participé en ese movimiento con mis colaboraciones en la Revista "Verde" de Cataguazes y la Revista de "Antropofagia" de San Pablo. En un capítulo de mi libro "El Arquero", que titulara "El Arte y la locura", definí el arte de los locos y lo diferenciaba del cubismo, y otras formas artísticas innovadores que hoy no causan extrañeza y pavor entre los pacatos. La tendencia que en el Río de la Plata y en toda América se llamó modernismo, coincide con el contenido estético y el culto de la forma, del parnasianismo y el simbolismo en el Brasil.

El modernismo en el Uruguay contribuyó a la superación del lugar común, al culto đe la forma, a la exaltación de la belleza como fin primordial de la vida, y aunque degeneró en un decadentismo de mal gusto en Roberto de las Carreras y del que no está exento Herrera y Reissig en algunos de sus poemas, su influencia benéfica no debe descartarse en la evolución de la literatura uruguaya, al superar el 
romanticismo de fin de siglo y la ramplonería de una poesía doméstica y epistolar. El iniciadar de este movimiento de liberación del vocablo pedrestre o enmohecido, de la idea ingráviờa, de la sensiblería que no es sensibilidad, fue José Enrique Rodó que en 1900 al publicar "Ariel" ya revelaba la magia de su estilo, su sensibilidad de fino artista $y$ su amor a la cultura. Eran aspectos de superación comparados con el desaliño de los románticos expresado en un estilo fácil sin gracia ni ritmo. Fue Rodó quien trajo en "Ariel" a la literatura uruguaya el culto de Grecia, el amor al platonismo y al noble ocio de la cultura. Los modernistas retomaron en sus gustos helenizantes, la huella de los parnasianos, adornaron sus poemas con faunos y cantos pánicos; la siringa fue el instrumento predilecto de Rubén Dario por oposición a la lira ơe los poetas románticos que queđó archivada para siempre. Los centauros fueron simbolos de creaciones paganas de "la tierra del Mirto", entre galopares de potros y de centauros resuscitó el dios Pan. Rodó captó el alma helénica y la sincretizó con el pensamiento cristiano: en esta amalgama se unen San Agustín y Platón, y la unidad espiritual del pensamiento. pagano-cristiano es para Rođó sintesis a la vez d’e amor y belleza. Rodó fue también el analista exquisito del modernismo en el ensayo que dedicó a "Prosas Profanas". Excesivamente minucioso en el detalle, con la técnica no muy acertada de analizar poema por poema, Rođó, no obstante comprendió con su sagaz y fino intelecto la fastusioỏad lírica de Darío; su amor por lo exótico, su odio a lo vulgar, su aristocratismo intelectual. Rodó no solamente fue mođ̉ernista por sus temas, lo fue más aún por su estilo lleno de resonancias visuales, de frases bellas, de matizado cromatismo.

E! notcrnismo tiene desçe entonces carácter endémico en la literatura uruguaya, que adquiere en los primeros años del siglo XX, del 1900 a 1909 un marcado signo decadente, con caídas a mal gusto y al énfasis. En este período asiático del moảernismo uruguayo predomina la egolatría (Ego sum Imperator, habia dicho Herrera y Reissig; "Dejad descansar a los dioses") el nietzschismo, el anarquismo espiritual, el individualismo "a outrance". Es la época de los cenáculos li- 
terarios, con pontífices como el "Consistorio del Gay Saber"; donde pontificaba Quiroga; "La Torre de los Panoramas", trono de Herrera y Reissg, el Café Polobamba - que tenía como pontífice máximo a Roberto de las Carreras, rey persa con su cohorte de sátrapas literarios reclutados en la bohemia cafeteril, con poses donjuanescas y byronianas, con su chaleco espectacular, su galerita requintada, su corbata anchurosa y su desafiante melena, pavonéando por las calles de la gran aldea que era Montevideo en esa época (1900) con su junquito escarcedor. Esta literatura que representaba el culto de la personalidad, no carece de ironía y gracia. Se manifiesta en ediciones lujosas, "art nouveau"; pero sin dejar nada de profundo o perdurable. Su decadentismo no dejó de inficionar a grandes poetas, como Herrera y Reissig; de ella se salvó Rodó por su serenidad helénica y su buen gusto. Otros poetas de este período, que más tarde evolucionaron hacia formas más clásicas o tradicionales, fueron Paul Minelli y González, que por devoción a Verlaine, firma Paul, y no Pablo, como lo hace ahora, que contribuyó con sus "Mujeres Flacas" al movimiento modernista uruguayo; Carlos María de Vallejo, que incursionó más tarde en el romance y la canción infantil, Julio Lerena Joanicó, Toribio Vidal Bello: todos ellos asiouos concurrentes a la Torre de los Panoramas.

Horacio Quiroga contribuyó al modernismo uruguayo con su único libro de poesías "Los arrecifes de coral". Su tendencia al realismo en sus cuentos y su amor a la naturaleza, lo alejó de aquella fantasía de imitación parisina de sus primeras creaciones. No era su fuerte escribir el cuento galante y sensual; el trajinar con la naturaleza selvática, su destino trágico, su amor a la soledad y su contacto con la humanidad desclasada ue lucha contra los peligros de la selva, estimularon al narrador original que tiene puntos de contacto a la vez con Poe y Kipling. Quiroga pontificó en el Consistorio del Gay Saber, típico cenáculo modernista donde se veneró a Lugones como a un semidiós. Pertenecieron a este cenáculo, además de Quiroga, el hoy consagrado historiador, José María Fernández Salơnana, que entonces componía versos y era aficionado al dibujo, Asdrubal Delgado, ale- 
jado hoy de las letras, exclusivamente dedicado al bufete de abogado; José María Delgado, hermano del anterior, médico y poeta, que escribió malos libros de poesía, y una buena prosa.

Dentro del mođernismo ácrata y revolucionario (una modalidad original del modernismo uruguayo), debemos ubicar a los poetas que cultivaron el tema social. Anarquistas o socialistas en sus ideas, whitmanianos por el acento, echaron las bases de la poesía social uruguaya. Tres figuras se destacan: Vasseur, Grugoni y Falco.

Alvaro Armándo Vasseur, de apellido francés, vivió gran parte de su vida en España e Italia, refugiándose en sus últimos años en la Capua infortunada de Montevideo, donde a pesar de que Vasseur ocupa un sillón en la Academia de Letras, no se le han reconocido sus grandes méritos. En sus "Cantos Augurales" y "Cantos del Otro Yo", se adelanta al Futurismo de Marinetti, y crea la poesia social influido por la potente palanca de Walt Whitman, que traduce al castellano, lo mismo que la prosa de Lafcaởio Hearn, los pensamientos de Soren Kierkeggard y otras páginas publicadas por la Editorial América, de Madrid. Sus últimos libros: "El Vino de la sombra" y "Yacia el Gran Silencio" tienen un tono más intimo y musical. La poesía de Vasseur es rica, vibrante e irregular. Todavía no se ha calibrado bien su influencia en el modernismo. Emilio Frugoni, parlamentarista de empuje, orador apasionado, ex-embajador en la URSS, fundador del partiơo socialista uruguayo, es hoy una figura venerable y venerada đe las letras uruguayas. Su contribución más importante al modernismo se encuentra en sus primeros libros "Bajo tu ventana" (1900), "De lo más hondo" (1902) y "El Eterno Cantar" (1907), donde se confunden la personalidad romántica y modernista del poeta; pero fue en sus últimos libros "Los Himnos" (1916) y "La Epopeya de la Ciudad" en los que, bajo la influencia de las nuevas escuelas y tendencias sociales, Frugoni se convierte en el poeta social, y el poeta de la ciudad, dos modalidades de sus últimas obras líricas. 
Angel Falco se inicia en 1906 con una modalidad épico-lírica donde expresa sus ideas anárquicas y su impetuoso ci vismo: "Ave Francia" (1906), "Cantos Rojos", "Garibaldi" (1907), y "Vida que Canta" (1908). Evoluciona como Vasseur en sus últimos años hacia una poesía más intimista, y deja de ser el poeta de las masasobreras, contrariamente a Frugoni que se inicia como poeta amatorio $\mathrm{y}$ evoluciona hacia el civismo de alto vuelo.

Discutible es la inclusión de Javier de Viana entre los escritores modernistas uruguayos: algunos aspectos de su obra como el uso del cromatismo como método de composición, lo aproximan al modernismo. Carlos Reyles el gran novelista de "La Raza de Caín", de "Beba" y "El Terruno" es otro escritor que contribuye al modernismo, no tanto en sus novelas, con excepción de "El Embrujo de Sevilla", en la que hace alarde de un coloriào que recuerda la paleta de Sorolla, como en sus ensayos, especialmente, en los más individualistas y nietzschianos, de "La Muerte del Cisne".

$\mathrm{Su}$ estilo es elegante y rico, con todos los matices que supieron decorar la prosa los modernistas. Artista refinado y erudito, Reyles fue un enemigo del lugar común, de la prosa ramplona y đỏesmayada.

Después de Rodó el más representativo de los modernistas uruguayos fue Julio Herrera y Reissig. Poeta hermético, refinado, de adjectivación precisa, metafórico y barroco. Sus poemas, especialmente los sonetos de "Los Peregrinos de Piedra", son joyas de perfección y belleza pura. Su estilo no siempre es barroco y alambicado, a veces es diáfano, como en Góngora se dan en el poeta de "Las Pascuas del Tiem" po", un tono oscuro, estilizado, a la vez que una visión sencilla de la naturaleza y de le paz aldeana. Su paisaje exótico y finamente estilizado, nada tiene que ver con las praderas uruguayas; su imaginación lo llevó a tierras lejanas y a países desconocióos para él, como el país vasco. Herrera y Reissig no vivió en Paris, como Rubén Darío o Amaởo Nervo. Su contacto con los poetas simbolistas franceses, particularmente con Albert Samain, cuyos poemas tradujo, fue 
puramente libresco. Identificándose con Rimbaud, Lautremont y Laforgue, Herrera y Reissig, le dió a su modernismo un contenido distinto al verleniano o banvilliano de Dario, y así fue más đ’ecadente que parnasiano o simbolista. Por ello, sobrepasó el modernismo y fue proclamado precursor del surrealismo por los poetas más nuevos de España. En Herrera y Reissig el horror del lugar común, el gusto por la metáfora, el uso đe la aliteración, el placer de lo exótico y lo raro, crearon en su obra una atmósfera tan personal que el poeta no vió el mundo a través de lo real y lo objectivo, sino a través de su sub-conciencia, y así vivió aislado en un ambiente de incomprensión, poseíało de sus extrañas elocubraciones, y seguro de su gloria, que los tiempos nuevos iban a reivindicar.

Hipersensible, sus sentidos captaban las sensaciones más imperceptibles para la percepción corriente, especialmente cromáticas, como se puede observar en estos ejemplos:

"Y el crepúsculo amarillo cuenta una historia secreta.

"Y hasta el estanque amatista donde termina el camino.

Sus colores predilectos eral el violeta, amarillo, blanco, rojo, azul, lila y verde. En una época en que los poetas a penas percibían el blanco o el verde. No menos ricas fueron sus sensaciones auditivas y olfativas:

"Picó la lluvia en crepitantes hilos."

"Junto a la fuente donde chocan las castañuelas los sapos"

"El bosque olía a mirras como un ara"

"De procaces sulfatos una impura

fragancia conspiraba a nuestro paso."

La poesia femenina contribuye al mođernismo uruguayo con dos grandes figuras: Delmira Agustini y María Eugenia Vaz Ferreira. Delmira Agustini, la "Safo" uruguaya, tuvo un concepto pagano de la belleza y del amor. Sus primeros poemas fueron celebrados por Rubén Darío, que vio en ella, a la niña genial que auguraba un nuevo camino en la poe- 
sía, al iniciarse con un libro de pureza virginal "El Libro Blanco". Delmira Agustini, después en "Los Calices vacíos" expresó lo más encendido de su sensualidad de mujer. Su sensualismo no es un erotismo vulgar, sino una sensualiơad trágica y espiritual. Siguió la trayectoria de su aciago destino como una estrella que recorre el firmamento y brilló con luz propia cuando otros cáian en la imitación. Carlos Vaz Ferreira, el ilustre filósofo uruguayo, habló del milagro cuanào la aparición de sus primeros versos, y Gabriela Mistrai confesó que de ella venían todas las poetisas de América.

Su canto a Eros, dios del amor, es una plegaria pagana:

"Eros, yo quiero guiarte, Padre ciego...

Pido a tus manos todopoderosas

$\mathrm{Su}$ cuerpo excelso derramado en fuego

sobre mi cuerpo desmayado en rosas."

María Eugenia Vaz Ferreira, la llamó Zum Felde: "La gran desterrada del amor, la poetisa erguida sobre la rosa solitaria de su orgullo. Y Esther de Cáceres agrega, en una de sus finas exégesis: "Austeridad, luz interior, espíritu. De esta vida de soled'ad sale su sentido heroico." María Eugenia Vaz Ferreira, como esos pintores de colores sombríos, llena de sombra la luz de su diáfana poesía, donde el ensueño se recoge en éxtasis de plegaria.

El modernismo en el Uruguay reveló poetas de la trascendencia de Herrera y Reissig, y en un tono menos original a Vasseur, Frugoni o Quiroga, a prosistas como Reyles y Rodó. Por este solo aporte merece destacanse en el modernismo americano; así lo han señalado críticos de la solvencia de Zum Felde, Max Henríquez Ureña, Arturo Torres Rioseco. Contribuyó en los comienzos del siglo como puente de salvación entre el romanticismo y las tendencias actuales, a la superación ảe la literatura uruguaya, que sin la intervención salvadora del modernismo, se hubiera prolongado en su postromanticismo intrascendente. Creó un ambiente de auténtico lirismo, no obstante sus defectos y la intrascendencia de 
muchas de sus creaciones. Tuvo aspectos originales, como el carácter social y cívico que adoptaron un grupo de sus poetas. Enalteció el verso perfeccionando las formas métricas, a través de la metáfora y otros módulos de la belleza poética, enriqueció el lenguaje, cultivó la frase bella llena de colorido y plasticidad, y no obstante los defectos que ya senalamos, fue el camino abierto a las nuevas escuelas y tendencias que buscaron una expresión más original y autóctona a la vez. 